
Digitized by the Internet Archive in 2011 with funding from University of Toronto 

Life Sciences Contributions 76
Royal Ontario Museum

Preliminary Studies of the Ultrastructure of Selected Ordovician Conodonts

ROYAL ONTARIO MUSEUM LIBRARIES

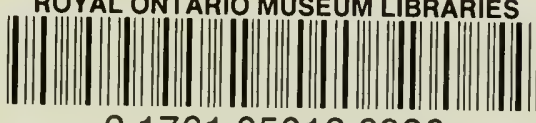

З 1761050136936

C. R. Barnes, D. B. Sass, E. A. Monroe
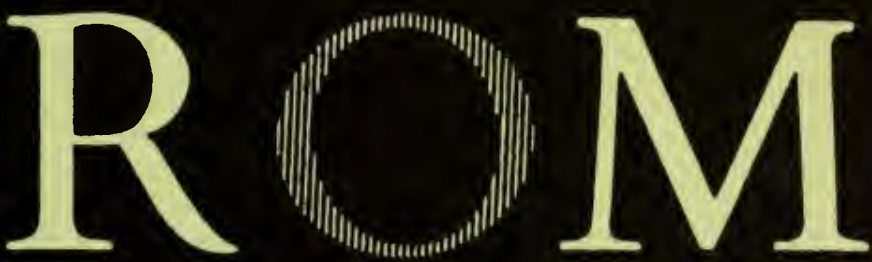

LIFE SCIENCES CONTRIBUTIONS

ROYAL ONTARIO MUSEUM

NUMBER 76

C. R. barnes, Preliminary Studies of the

D. B. SAss, Ultrastructure of Selected

E. A. monroe Ordovician Conodonts 


\section{ROYAL ONTARIO MUSEUM}

\section{PUBLICATIONS IN LIFE SCIENCES}

The Royal Ontario Museum publishes three series in the Life Sciences:

LIFE SCIENCES CONTRIBUTIONS, a numbered series of originạl scientific publications, including monographic works.

LIFE SCIENCES OCCASIONAL PAPERS, a numbered series of original scientific publications, primarily short and usually of taxonomic significance.

LIFE SCIENCES MISCELLANEOUS PUBLICATIONS, an unnumbered series of publications of varied subject matter and format.

All manuscripts considered for publication are subject to the scrutiny and editorial policies of the Life Sciences Editorial Board, and to review by persons outside the Museum staff who are authorities in the particular field involved.

LIFE SCIENCES EDITORIAL BOARD, 1969-1970

Chairman: P. C. SWANN

Director, Royal Ontario Museum

Editors: R. L. PETERSON

E. J. CROSSMAN

CHRISTOPHER R. BARNes is a Research Associate, Department of Invertebrate Palaeontology, Royal Ontario Museum, and a member of the Department of Earth Sciences, University of Waterloo, Waterloo, Ontario.

DANIEL B. SASS is with the Department of Geology, Alfred University, Alfred, N.Y.

EUgene A. MONRoE is with the State University of New York, College of Ceramics, Alfred, N.Y.

PRICE： $\$ 2.00$

(C)The Royal Ontario Museum, 1970

100 Queen's Park, Toronto, Canada

PRINTED BY MCCORQUODALE \& BLADES PRINTERS LIMITED 


\title{
Preliminary Studies of the Ultrastructure of Selected Ordovician Conodonts
}

\begin{abstract}
The internal structure of three representative Ordovican conodont form-species (Drepanodus homocurvatus Lindstrom, Polycaulodus bidentatus Branson and Mehl, and Ptiloconus gracilis (Branson and Mehl)) is investigated using transmission and scanning electron-microscopes. Specimens of these species show significant differences, with some similarities, in the character and arrangement of the crystallites that build individual lamellae. In Polycaulodus bidentatus, minute spheres are noted that may be analogous to the holes previously described from the white matter of certain lamellar conodonts. The results indicate that the internal structure may eventually prove to be a valuable criterion in taxonomic and phylogenetic conodont studies.
\end{abstract}

\section{Introduction}

Investigations into the internal structure of conodonts have been limited compared to many other fossil groups. This, despite the observation of Lindström (1964, p. 22) that "one may assume a priori that the inner structure must have a great systematic significance, greater perhaps than that of the surface morphology." Lindström continued, "in fact the most important line of division in conodont taxonomy is generally drawn according to inner structure," i.e. the separation of the "fibrous" and lamellar conodonts.

Early studies using standard optical methods were undertaken by some conodont workers, notably Pander (1856), Hass (1941), Gross (1954, 1957, 1960), and Rhodes and Wingard (1957). These were reviewed and amplified by Lindström (1964). More recently, investigations using electron microscopy have been made by Pietzner et al. (1968), Pierce and Langenheim (1969), and our own studies.

The earlier workers established that conodonts were constructed by a series of lamellae deposited outwardly (centrifugally) upon one another. Accelerated and retarded lamellar growth and the extent of overlapping and/or retreat of the lamellae edges relative to the preceding one largely controlled the external morphology of the conodont. Initial growth always started from the basal cavity area. Within many conodonts are areas of white, optically opaque material that Lindström $(1955,1964)$ has termed 
white matter. This material is commonly found in the denticles rather than the basal zone of the conodont. Lindström (1964) postulated that the white matter represented a zone of demineralization in which phosphatic material was removed during growth to supply other centres of rapid structural growth. Lindström (1964) and Pietzner et al. (1968) have also studied the microstructure of the basal fillings commonly found attached to the basal cavity.

The two principal problems in conodont paleobiology are their biological affinities and the character of the natural assemblages. We believe that detailed knowledge of internal structure will provide valuable information pertinent to both problems. First, the growth pattern of conodonts is apparently unique and the use of phosphate for skeletal materials is limited to relatively few fossil groups. More knowledge on the exact mode of growth may thus provide a greater insight into their biological affinities. Second, conodonts have been found in natural assemblages, especially in Pennsylvanian black shales (e.g. Rhodes, 1962). Recently, Bergström and Sweet (1966), Schopf (1966), Webers (1966), and Kohut (1969) have established consistent groupings of conodonts in Ordovician strata based on common geographic and stratigraphic occurrence and their presence in constant ratios. It appears likely that in future research natural conodont species can be established without the prerequisite of finding natural assemblages. If so, what chance might there be to group these into larger natural taxa and establish natural phylogenies? One promising approach would be to find important differences of internal structure and growth pattern.

The advent of the transmission and scanning electron microscopes has enabled studies on ultrastructure to be significantly advanced. For the first time, the structure of individual laminae can be determined and especially their spatial relationships to each other.

Our first investigations began in 1965 with a variety of form-species. The results convinced us of the potential of the electron microscope studies and it was decided to concentrate on four form-species: Drepanodus homocurvatus Lindström, Belodina compressa (Branson and Mehl), Polycaulodus bidentatus Branson and Mehl, and Ptiloconus gracilis (Branson and Mehl). The former two are lamellar conodonts, the first being a large single cone that has little complexity in the laminae; the latter two are "fibrous" conodonts, $P$. bidentatus being a massive variety and Pt. gracilis a more delicate perhaps transitional form. Only in Belodina compressa is there any significant white matter. It was hoped therefore to establish if there are any significant structural differences between the "fibrous" and lamellar conodonts.

The specimens (several of each form-species were used) were all derived from Middle Ordovician strata of Ontario and Quebec. The limestones belong to the Black River Group; the stratigraphy of the area and the localities of the sections from which specimens used in this study were secured are detailed in Barnes (1967). The specimens were obtained from flat-lying, undeformed limestones from which they were extracted using standard procedures of $10-15 \%$ acetic acid, heavy-liquid (bromo- 
form) separation, and magnetic separation. The procedures are not considered to have had any effect on the internal structure.

This present report is preliminary, using specimens of a few formspecies from a limited stratigraphic sequence. The results reveal the internal structure of a simple lamellar conodont (D. homocurvatus) unaffected by the complexities of white matter and that of the two "fibrous" form-species ( $P$. bidentatus, $P t$. gracilis). Clearly many more form-species need to be investigated and this we intend to do, concentrating on some possible natural groupings of form-species. There may well be significant changes in the mode of growth through time of the conodont skeletal parts, hence much investigation is necessary on specimens selected from Cambrian through Triassic strata.

The results of studies using specimens of Belodina, Panderodus, and other conodonts possessing white matter will be published later.

\section{Procedures and Techniques}

The micromorphology of the surface of D. homocurvatus, P. bidentatus, and Pt. gracilis was examined with the Stereoscan (P1. I, figs. 2, 4, 6). Subtle differences can be observed but this type of study is far less revealing than the examination of oriented sections through the conodont.

Several specimens of each form-species were used in this study and each was individually embedded and oriented in Bio-Plastic. The embedded specimen was then ground to the level of section desired and finally polished using 0.003 grade aluminium oxide powder. The polished surface was then etched with $2 \mathrm{~N} \mathrm{HC1}$ and an acetate peel taken for transmission electron microscope (TEM) study. The same etched surface was then examined using the scanning electron microscope (SEM). The electron microscopes used were the RCA EMU-3B, the Hitachi-11, and the Cambridge Stereoscan.

\section{Drepanodus homocurvatus Lindström}

D. homocurvatus (Pl. I, fig. 1) is common throughout much of the Ordovician with a wide geographic distribution and is especially abundant in the Middle and Upper Ordovician strata of midcontinental North America. It is a simple cone with a growth axis extending in a smooth curve from the apex of the basal cavity to the tip of the cusp. Commonly, white matter is absent in this form except for possible development along the growth axis. In well preserved specimens, the major interlamellar spaces can be locally observed, especially adjacent to the growth axis. The growth lamellae are clearly visible along the inside of the basal cavity where they overlap earlier lamellae to produce the expansive cavity.

Several specimens were examined in both longitudinal and obliquetransverse sections. It proved difficult to secure good transverse sections that were exactly normal to the growth axis but in the oblique-transverse sections the specimens were ground down to the level of the growth axis. Traverses across the sections were made using both transmission and scanning methods. 
The apex of the basal cavity represents the initial point of growth of a conodont. Pietzner et al. (1968) made extensive studies on the character of the initial lamella that produced the small basal pit on platform conodonts. In D. homocurvatus the first lamellae are not simple cone-in-cone structures around the growth axis. Pl. IV, fig. 2 illustrates that along the initial part of the growth axis the lamellae on the posterior side unconformably overlap those on the anterior side of the axis. Above a point about one-tenth the length of the axis from the cavity apex, the lamellae run parallel to each other and are continuous across and presumably around the growth axis. As the lamellae approach the growth axis from the posterior side they bend upwards, and increase slightly in thickness as do the interlamellar spaces. Lindström (1964, p. 17) noted that "Rapid growth could evidently take place in three ways, either through intercalation of additional lamellae at the fastest growing points, or through a thickening of the lamellae, or through spaces being left between the successive lamellae. The first of these alternatives seems not to have been observed with certainty in conodonts." In $D$. homocurvatus the latter two alternatives are observed; the first alternative is, in fact, demonstrable in Ptiloconus gracilis described below.

The study of Pietzner et al. (1968) devoted much attention to the character of the individual lamellae and the component crystallites that comprise them. However, the ultramicrotome sectioning of the lamellae may have disturbed the orientation of the crystallites. Consequently, they were not able to establish with certainty the orientation of the minute crystallites that build the lamellae. In the current study the Stereoscan photomicrographs of the etched oriented sections illustrate the internal structure of the lamellae for each species.

Most of the sections through $D$. homocurvatus do not show well defined lamellae. These are best seen in Pl. IV, fig. 2 where the lamellae range in thickness from $1 \mu$ to over $5 \mu$ as they thicken towards the growth axis. But in other photomicrographs of this species, the lamellae are well defined only along parts of their course (e.g. Pl. II, fig. 2). The reason for this is apparent from the scanning photomicrograph traverses (Pl. III, figs. 3a-è; Pl. IV, figs. 3a-d). The lamellae are individually constructed of rather massive columns and irregular sheets that lie parallel to the growth axis. The columns and sheets have irregular margins and consequently the thickness of the lamellae is variable. Locally, distinct interlamellar spaces are present, while elsewhere adjacent lamellae appear to be fused together with no interlamellar space.

\section{PLATE I}

Electron micrographs (SEM) of specimens of the three conodont form-species studied and their surface micromorphology at points marked by arrows. Longitudinal lamellar structure is evident, but the detailed structure is obscure. Figs. 1, 2, Drepanodus homocurvatus; Figs. 3, 4, Polycaulodus bidentatus; Figs. 5, 6, Ptiloconus gracilis. Scale measures $100 \mu$ in Figs. 1, 3, 5 and $1 \mu$ in Figs. 2, 4, 6. 

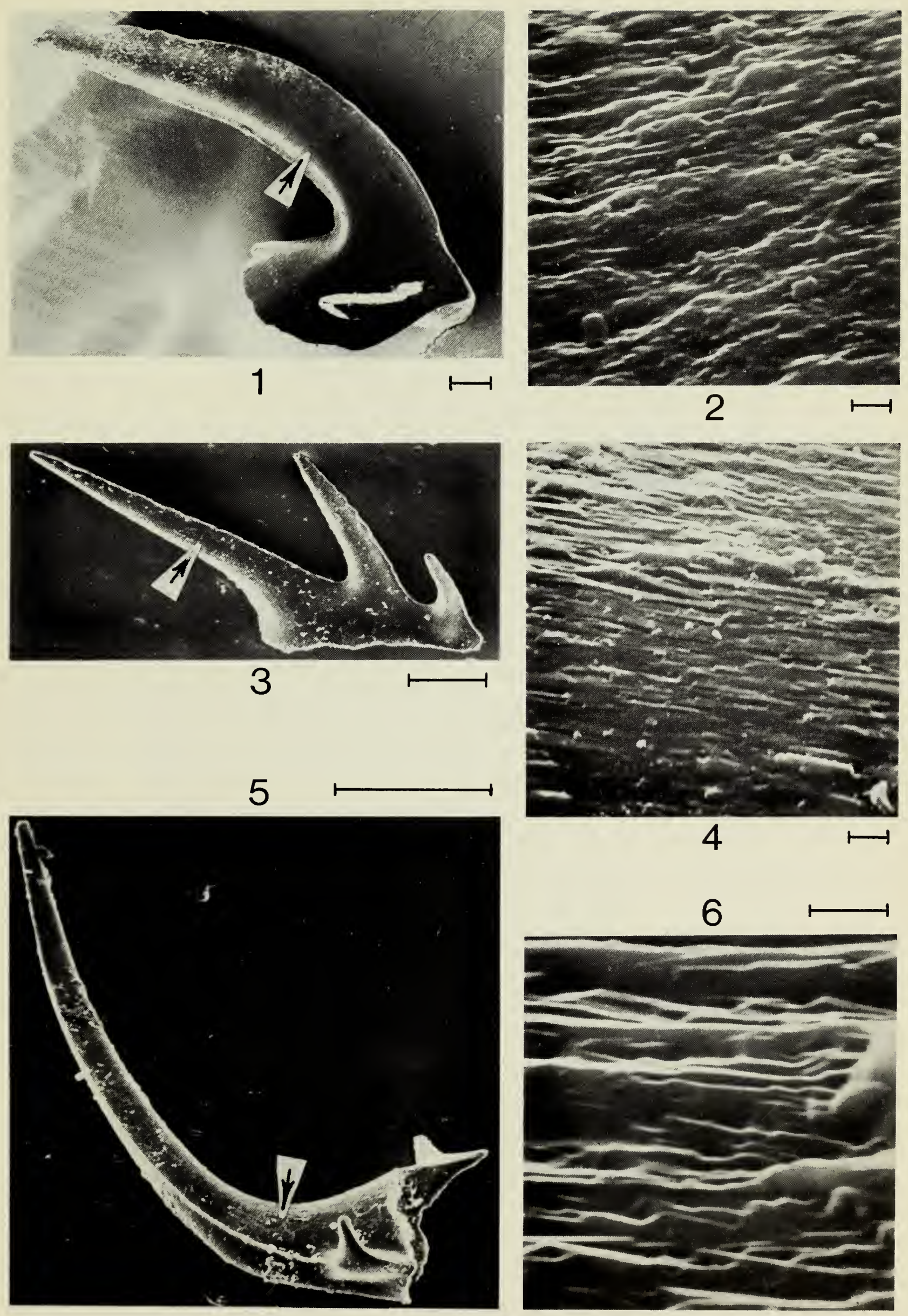
The lack of wide persistent interlamellar spaces makes it difficult to trace and recognize individual lamellae. Lamellae were shown above to be constructed, in rather irregular manner, of rods or sheets rather than of regularly arranged equigranular crystallites that were present in some of the specimens described by Pietzner et al. (1968). Empty spaces and channels exist between the rods and sheets. Their geometry is correspondingly as complicated as the irregularity of the walls of the rods and sheets, and appears as linear grooves and channels (PI. III, fig. 1). Because of the irregular form of the lamellae, the grooves are locally covered or are terminated, and subcircular openings into channels just below the etched surface are commonly seen (Pl. II, fig. 2; Pl. III, fig. 1).

\section{Polycaulodus bidentatus Branson and Mehl}

The specimens used belong to the form-species P. bidentatus (Pl. I, fig. 3), which includes a transition series involving several forms previously referred to a number of separate species. Those used belong to the variety named $P$. tridentatus Branson and Mehl. Specimens of the form-species are common in the Middle Ordovician in midcontinental North America. Specimens are morphologically simple, and are composed of three robust denticles of subcircular cross-section which rise from a lenticular base that has a shallow basal excavation. Polycaulodus is a typical representative of conodonts commonly called "fibrous" (e.g. Lindström, 1964, pp. 22-24).

Specimens were examined both in longitudinal and transverse sections. The conodont-elements are constructed of a series of lamellae up to $5 \mu$ wide. The lamellae are not readily distinguished in the inner part of the denticles (Pl. VI, figs. lc-f, 2) but distinct interlamellar spaces are present towards the margins. The width of the individual lamellae appears to remain fairly constant when traced laterally.

Each lamella is constructed of a multitude of minute $(0.2 \mu$ diameter $)$ crystallite-like rods oriented parallel to the interlamellar spaces. This relationship is shown in Pl. VIII, fig. 5a. The rods are seemingly arranged in microlamellae but these are replaced laterally by other microlamellae. The rods are clustered together and can appear as parallel rods (P1. VIII, fig. $5 \mathrm{a}$ ) or partial sheets (Pl. VIII, fig. 5c). Transverse (cross-sectional) views through the rods (Pl. VIII, figs. 1-3) illustrate their prismatic nature.

PLATE II

Oblique-transverse sections (SEM and TEM) through cusp of Drepanodus homocurvatus. Sections taken at point of greatest curvature, cutting the anterior margin and ground down to the level of the growth axis.

Fig. 1 General view. Lamellae seen to bend sharply around central growth axis. Arrow indicates area enlarged in lower part of Fig. 2 and in Pl. III, Fig. 1. Scale measures $25 \mu$.

Fig. 2 Composite (TEM) traverse along specimen. Individual lamellae are well defined only along parts of their length by grooves and channels. Lamellae vary in thickness along their length, and bend sharply along the trace of the growth axis (vertical arrow). Horizontal arrow indicates fracture zone. Scale measures $5 \mu$. 

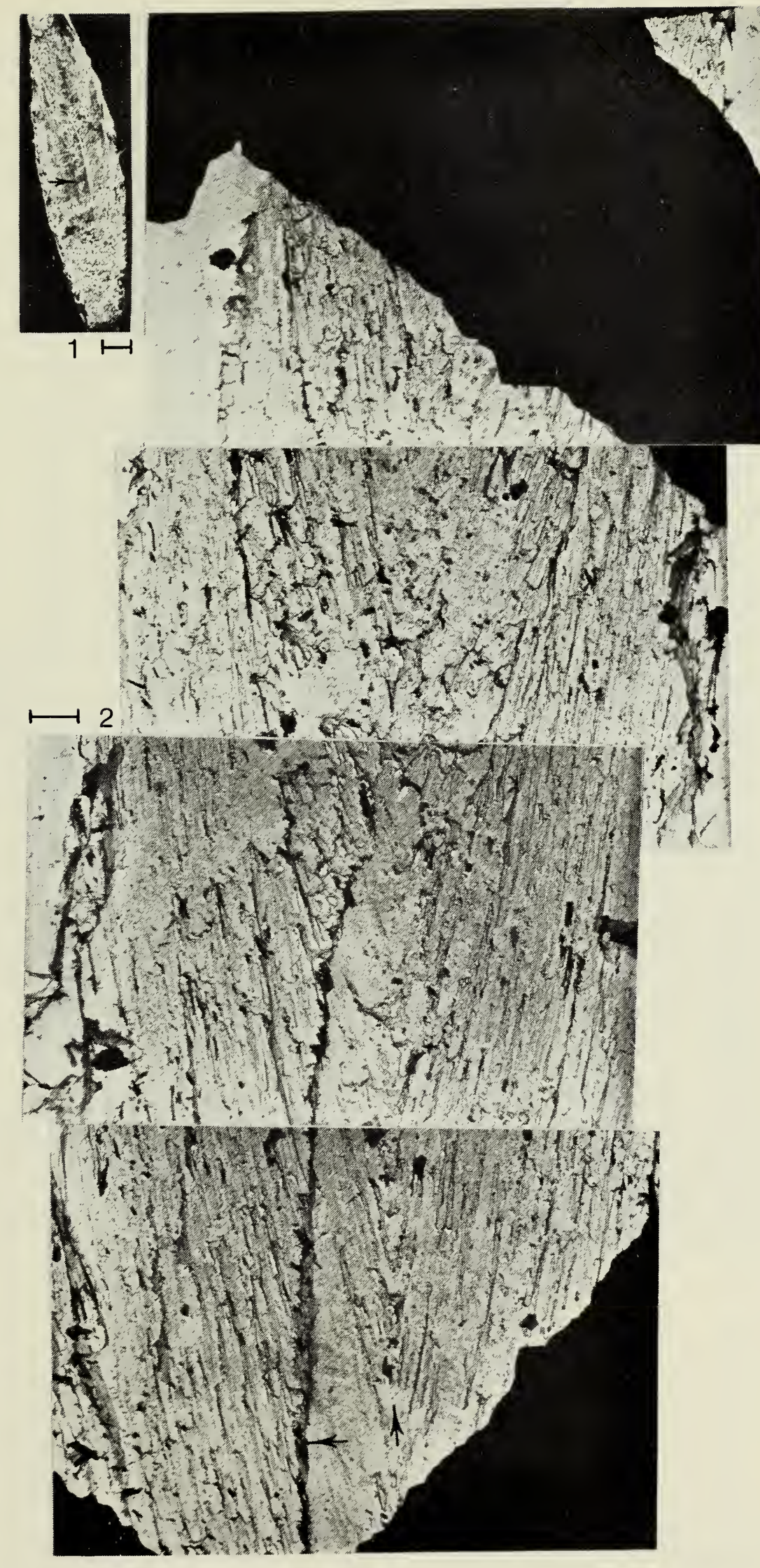
Longitudinal sections through Polycaulodus bidentatus (Pl. V, fig. 1; Pl. VI, figs. 1a, b, g) illustrate the long linear nature of the rods and also reveal another distinctive structural feature, spheres. The latter are minute (approximately .05-.1 $\mu$ in diameter) dome-like structures found in abundance on the surface of longitudinal sections. In some electron photomicrographs (Pl. VII, figs. 1,3) they are observed to lie in rows along the length of the rods but in others (Pl. VI, figs. 1a-g) the distribution does not appear regular. In some instances, there was doubt as to whether the structures were positive or negative in relief but scanning with the aid of the Y-modulator on the Stereoscan (Pl. VII, fig. 2) showed all to be positive. The variable size of the spheres, their circular shape in oblique sections, and the dome-like shape of those exposed strongly favours interpreting them as spherical structures rather than as the surface expressions of deeply penetrating tubes.

In the shallow basal excavations of many "fibrous" conodonts (e.g. Polycaulodus, Curtognathus, Cardiodella, Trucherognathus) a small pit occurs at the base of the growth axis of the main cusp. The growth axis itself is obscure in the rather opaque "fibrous" conodonts compared with normal lamellar conodonts. In longitudinal section (Pl. VI, figs. 1d, e, 2) the growth axis is seen as an empty channel, circular in cross-section. The one illustrated varies in width along its length and closes before reaching the tip of the cusp. The central hollow growth axis is also observable in transverse sections across the denticles (Pl. VIII, figs. 3, 5) and in one (Pl. VIII, fig. 4) the channel appears to be bifid.

The specimens of Polycaulodus bidentatus used all showed another distinctive structure in at least one denticle: a sheet of coarsely crystalline material, oriented anterio-posteriorly and passing down the length of the denticle. The sheet thus splits the conodont element into two halves; on the exterior surface it is represented by the weakly keeled anterior and posterior margins of the denticles. The axial location of the sheet, passing through the central growth axis, is seen in Pl. VIII, figs. 1, 3 and the coarsely crystalline nature is illustrated in Pl. VIII, fig. 2. On transmission

PLATE III

Oblique-transverse sections (SEM) through the cusp of Drepanodus homocurvatus; orientation of the sections is the same as in PI. II.

Fig. 1 Detail of lower part of Pl. II, Fig. 2 (surrounding the two arrows) to illustrate details of lamellae and irregular interlamellar channels and grooves. Secondary fracture indicated by horizontal arrow. Scale measures $1 \mu$.

Fig. 2 General view of oblique-transverse section illustrating the arching of lamellae across the trace of the growth axis. Traverse between arrows depicted in Figs. 3a-e. Scale measures $10 \mu$.

Figs. 3a-e Traverse from left to right along line indicated in Fig. 2; illustrations cover $85 \%$ of total traverse. The irregular robust rod-like crystallites are seen throughout, being thicker in the centre (Figs. $3 \mathrm{~b}, \mathrm{c}$ ) and thinner towards the margins (Figs. 3a, e). Individual lamellae not well defined. Scale measures $1 \mu$. 

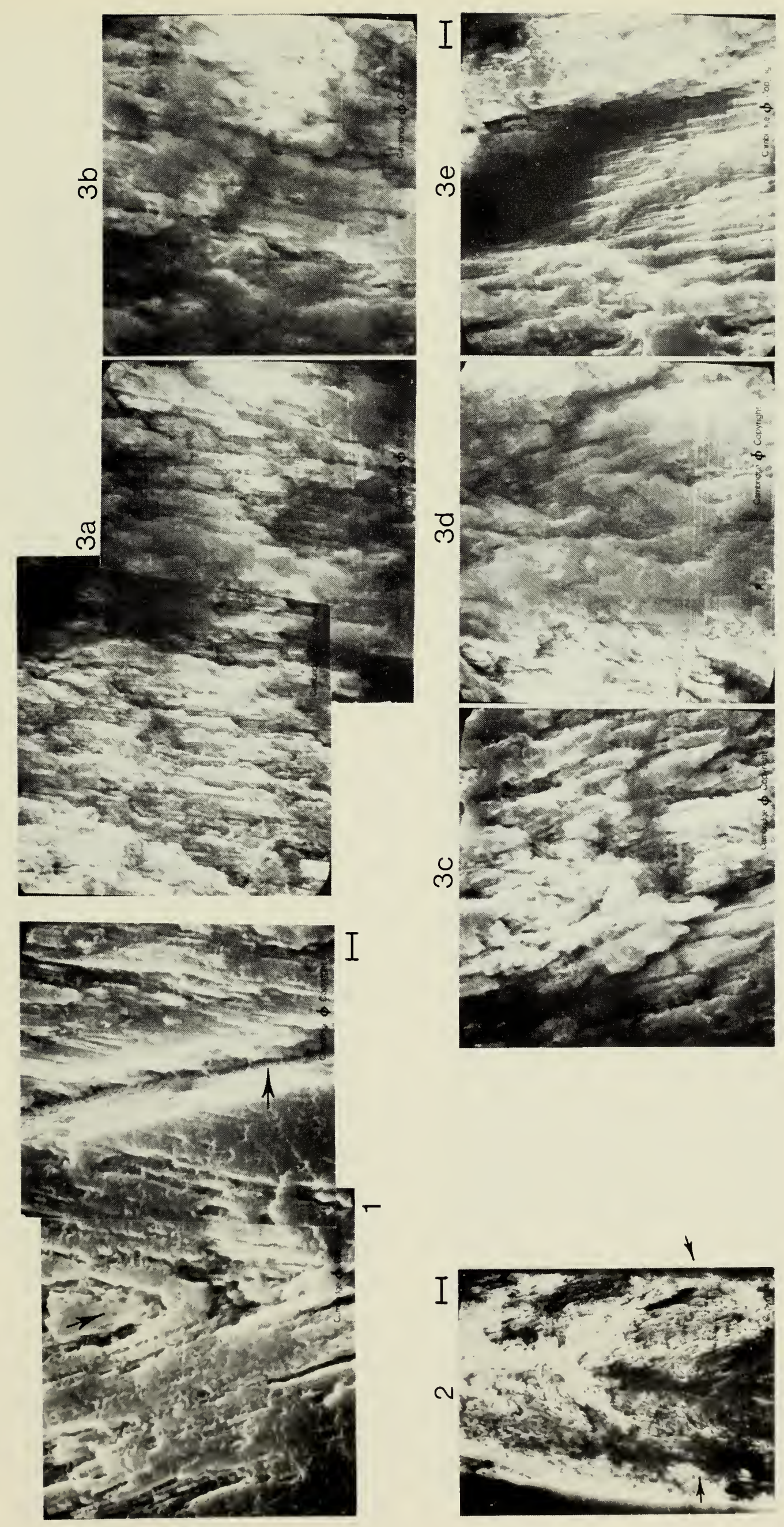
electron micrographs the blocky crystals are shown to average 2-3 $\mu$ in width and produce a clearly defined sheet with sharp, but somewhat irregular edges. It is not yet certain whether this sheet structure is a constant primary feature in $P$. bidentatus (and possibly other similar "fibrous" forms) or a secondary development in the specimens studied. Many more specimens will have to be sectioned to clarify this point.

\section{Ptiloconus gracilis (Branson and Mehl)}

Ptiloconus gracilis ( $\mathrm{Pl}$. I, fig. 5) is rather variable in the number and arrangement of minor lateral denticles above the expanded basal cavity. Andrews (1967, pp. 894-895) has regarded the form-species as part of a symmetry transition series within Erismodus. Both Erismodus (including Microcoelodus) and Ptiloconus have been regarded as "fibrous" conodonts. However, both are usually less robust than Polycaulodus and are not too dissimilar in general appearance from those lamellar conodonts lacking extensive white matter (e.g. Drepanodus). If there is a transitional stage between the "fibrous" and lamellar conodonts, a form such as Ptiloconus would approximate to it and for this reason this form-genus was studied. Ptiloconus, like Polycaulodus, is a common "fibrous" conodont found in Middle Ordovician strata in midcontinental North America.

Detailed study of Ptiloconus gracilis was restricted largely to a transverse section through the basal-cavity area. The conodont-element is constructed of well-defined lamellae, averaging 2-3 $\mu$ in thickness. The scanning photomicrographs ( $\mathrm{Pl}$. IX, fig. 1) show the lamellae to vary in thickness. Where the conodont-element increases in thickness (e.g. around the basal cavity) the individual lamellae likewise show an increase. Also additional, but thinner, lamellae are added but are not persistent laterally and are overlapped by the succeeding lamellae (see small arrow, Pl. IX, fig. 1). This mode of growth expansion was not observed by Lindström (1964, p. 17) using light microscopy. Lindström (ibid.) noted that another common method of expansion and rapid growth was to increase the width of the interlamellar spaces, but this is not evident in Ptiloconus gracilis.

PLATE IV

Longitudinal sections (SEM) of Drepanodus homocurvatus

Fig. 1 General view, laminated structure well shown. Small central arrow indicates growth axis. Traverse (Figs. 3a-d) taken from lateral arrow at anterior margin to central growth axis. Scale measures $100 \mu$.

Fig. 2 Detail of Fig. 1 at apex of basal cavity. Arrow marks central growth axis. Note unconformable and onlapping relationships of lamellae to the right (posterior) of growth axis and their variation in thickness. Scale measures $10 \mu$.

Figs. 3a-d Traverse from anterior margin to central growth axis along line indicated in Fig. 1. Three-quarters of total traverse represented in Figs. 3a-d. Near-vertical irregular crystallite sheets and rods are tightly fused and individual lamellae are not readily distinguished. Individual crystallites more apparent in Fig. 3d with the slight change in inclination as the growth axis is approached. Scale measures $1 \mu$. 

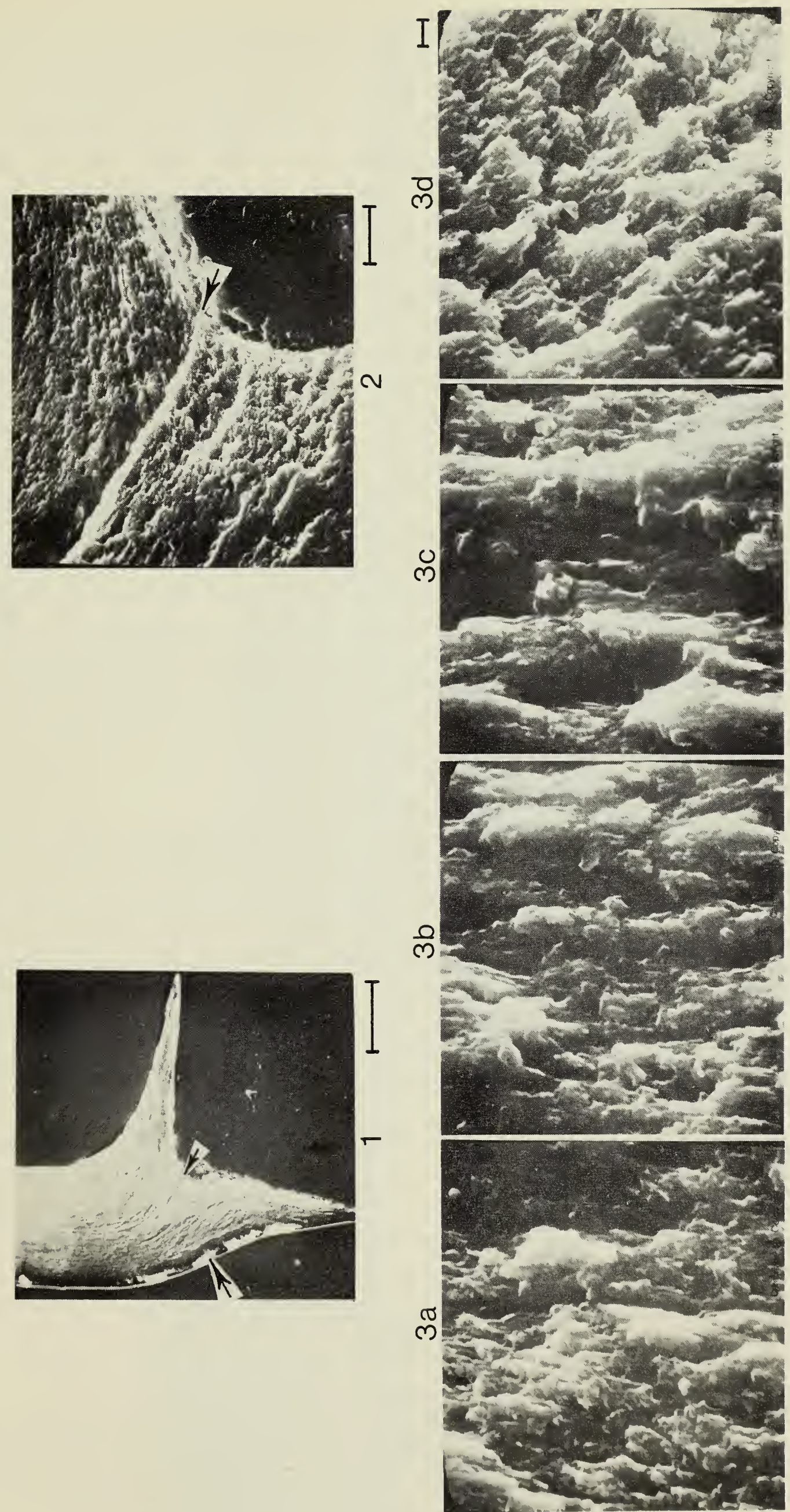
The lamellae in Ptiloconus gracilis (Pl. IX, fig. 2b) are constructed in a fashion different from both $D$. homocurvatus and $P$. bidentatus considered above. They are composed of a highly porous aggregate of flaky crystallites (Pl. IX, fig. 3). These appear to have almost random orientation, a wide range of size and shape, and no clearly defined structure. It is not clear how they are bound together unless it is by fusion at a few contact points. Many of the larger flaky crystallites are penetrated by holes in a random fashion (Pl. IX, figs. 2a-c). The crystallites are relatively large, commonly in the range $0.5-1.0 \mu$, and the larger ones at least tend to be oriented so that their long axes lie normal to the interlamellar spaces. However, as noted above, there is no general orientation pattern for the crystallites.

\section{Discussion}

From the foregoing descriptions, it is clear that the three form-species considered have significant differences in their internal structure. Such differences are welcome in that they offer promise that this criterion may be valuable in taxonomic and phylogenetic studies. At this early stage of electron-microscopic study of conodonts, it is premature to develop detailed interpretations of the meaning and function of all the structures observed. Each species was described as a separate entity and it is worthwhile at this stage to discuss the similarities and differences in their structures.

\section{Crystallites}

The smallest structural units, the crystallites, show considerable variation in shape between form-species. In Drepanodus homocurvatus they are illdefined, long, linear, and are oriented parallel to the interlamellar spaces. They commonly appear to be tightly fused yet perforated by tubes, some of which seem to be intercrystallite spaces. The crystallites in Polycaulodus bidentatus are likewise linear but are well defined and are more prismatic in shape. Their orientation is also parallel to the interlamellar spaces. In Ptiloconus gracilis, they are significantly different, being flat, flaky structures, somewhat perforated, and held together in a loose porous structure compared with the close packing of the former two. These crystallites have no well-defined orientation; many are oblique or normal to the interlamellar spaces, but overall the orientation appears to be random. In size the crystallites average $0.75 \mu, 0.2 \mu$, and $0.75 \mu$ for the three form-species respectively, although there is considerable variation in size within each specimen and commonly within a single lamella.

PLATE V

Fig. 1 Longitudinal composite section (TEM) through middle denticle, near tip, of Polycaulodus bidentatus. Section does not include the growth axis. Lamellae are well shown, somewhat thinner towards the margin, on the right, than in the centre, on the left. Scale measures $10 \mu$. 

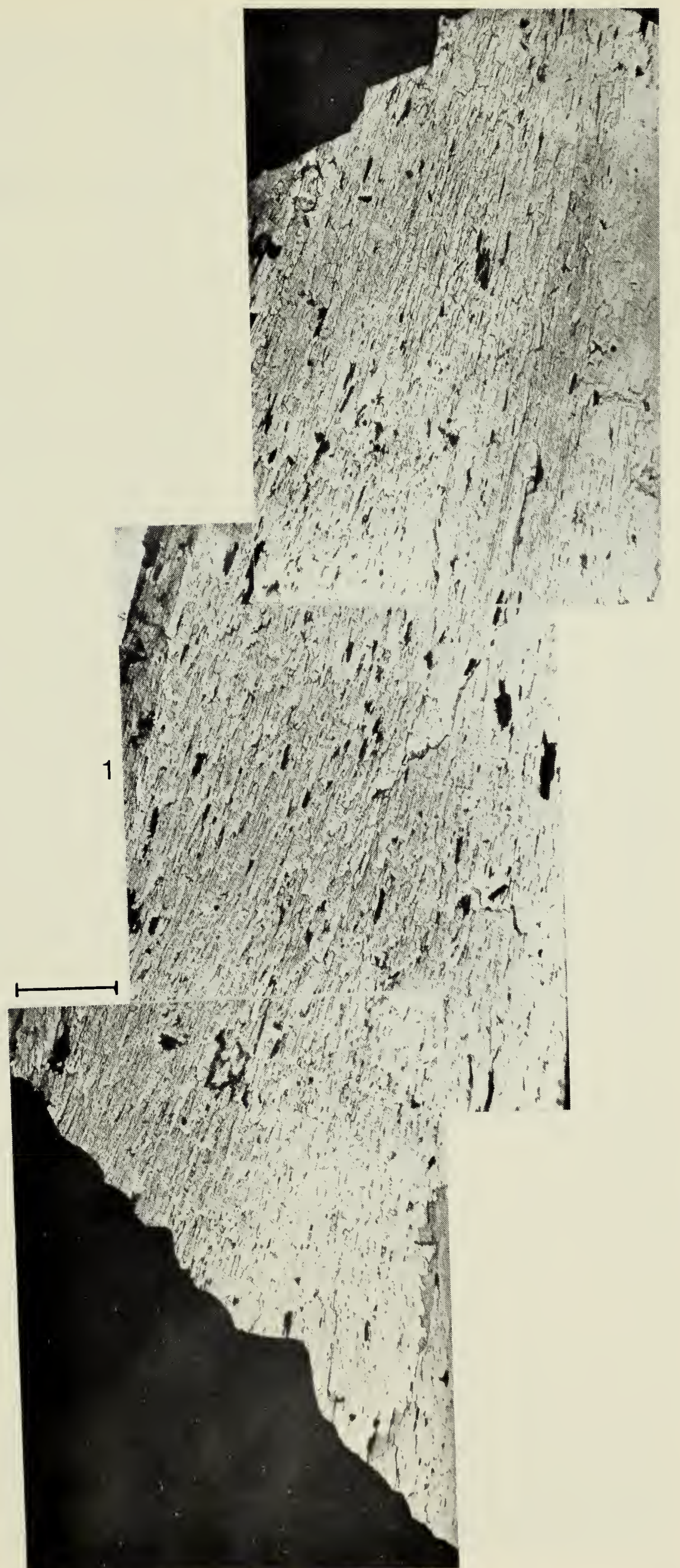
Hass (1941) and Lindström (1964) maintained that crystallites were developed perpendicular to the interlamellar spaces. Pietzner et al. (1968) noted alignments that were oblique to the spaces but noted that these may have been altered during the ultramicrotome sectioning of the specimens. The present study has established an orientation parallel to the spaces in two form-species and random or oblique orientation in another (Ptiloconus gracilis).

The earlier optical studies were unable to ascertain the shape of individual crystallites. Pietzner et al. (1968) illustrated several examples in which a closely packed prismatic form was evident (e.g. ibid., Pl. 20, fig. 2). These examples were of Devonian platform conodonts. The three form-species under discussion show much variation in shape from irregular rods and sheets, to prismatic crystallites, to flaky, porous structures.

None of the specimens under study possessed extensive white matter. Lindström (1964) and Pietzner et al. (1968) examined this material in detail and discovered that the white matter contained an abundance of minute holes, ranging in size from $0.2-1.0 \mu$, which are arranged in rows that may run perpendicular to each other. Pietzner et al. (1968, p. 147) summarized that "white matter may have replaced a different primary matter. One might conclude that the white matter represents an area of faster mineralization which most likely is also identical with the areas of fastest growth." The origin and function of the holes was not completely explained. However, these structures appear to be closely analogous to the smaller spheres observed in Polycaulodus bidentatus. These are circular in cross-section, approximately 0.05-0.1 $\mu$ in diameter, and locally are arranged in rows along the lamellae parallel to the growth axis of the cusp. It is likewise premature at this stage to conjecture on their origin and function except to note the possibility that during the supposed demineralization the material comprising the spheres was completely removed leaving a void rather than white matter. Peitzner et al. (1968, pp. 143144) noted that a volume difference must have occurred between the original tissue and the available mineral matter and the very numerous and

\section{PLATE VI}

Longitudinal sections (SEM) through main denticle of Polycaulodus bidentatus.

Figs. 1a-g Traverse across main denticle from left to right as indicated in Fig. 2. Illustrations comprise $70 \%$ of total traverse with some overlap in Figs. 1d and 1e. Central growth axis indicated by arrows in Figs. 1d, 1e is circular in cross-section. Individual lamellae and crystallites not visible in zone around growth axis, but are apparent towards the margins (Figs. 1a, b, g). Entire traverse shows high concentration of minute spheres. Scale measure $1 \mu$.

Fig. 2 General view showing line of traverse (Figs. 1a-g) between large arrows. Small arrow indicates the central growth axis. Individual lamellae are visible towards the margins. Dark area is plastic embedding medium; lower part of adjacent denticle seen at lower left. 


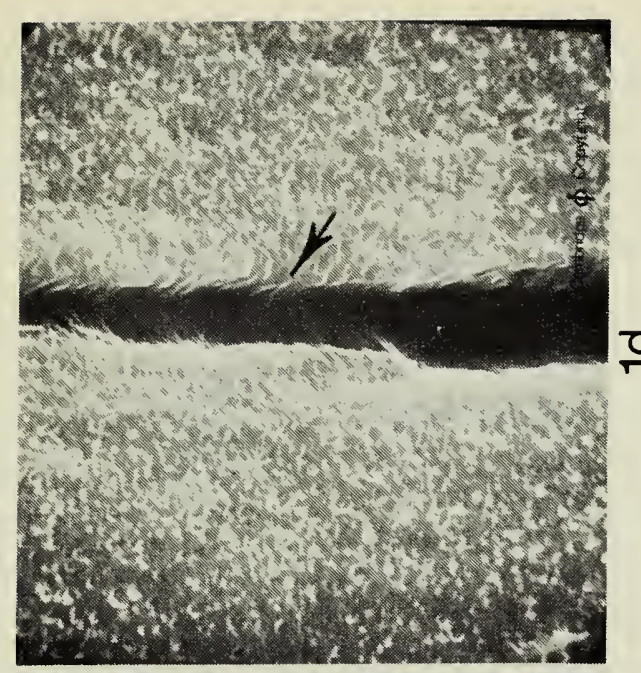

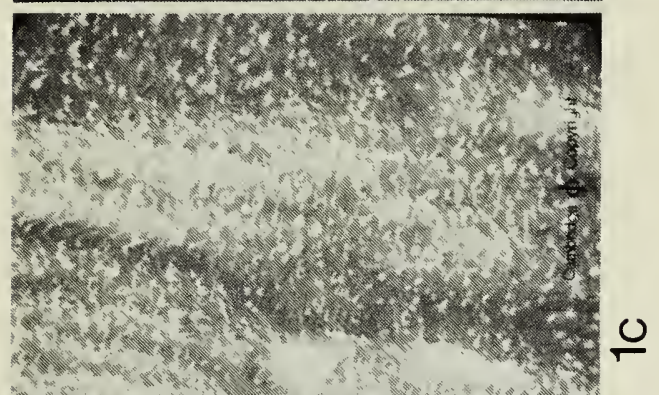

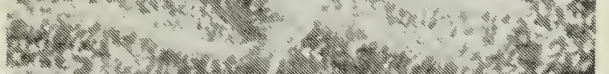
s.

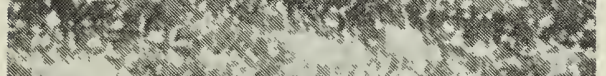

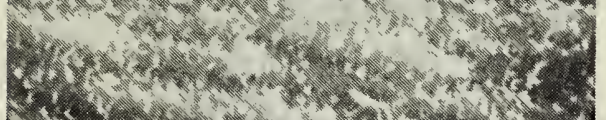

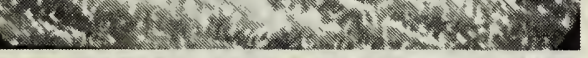
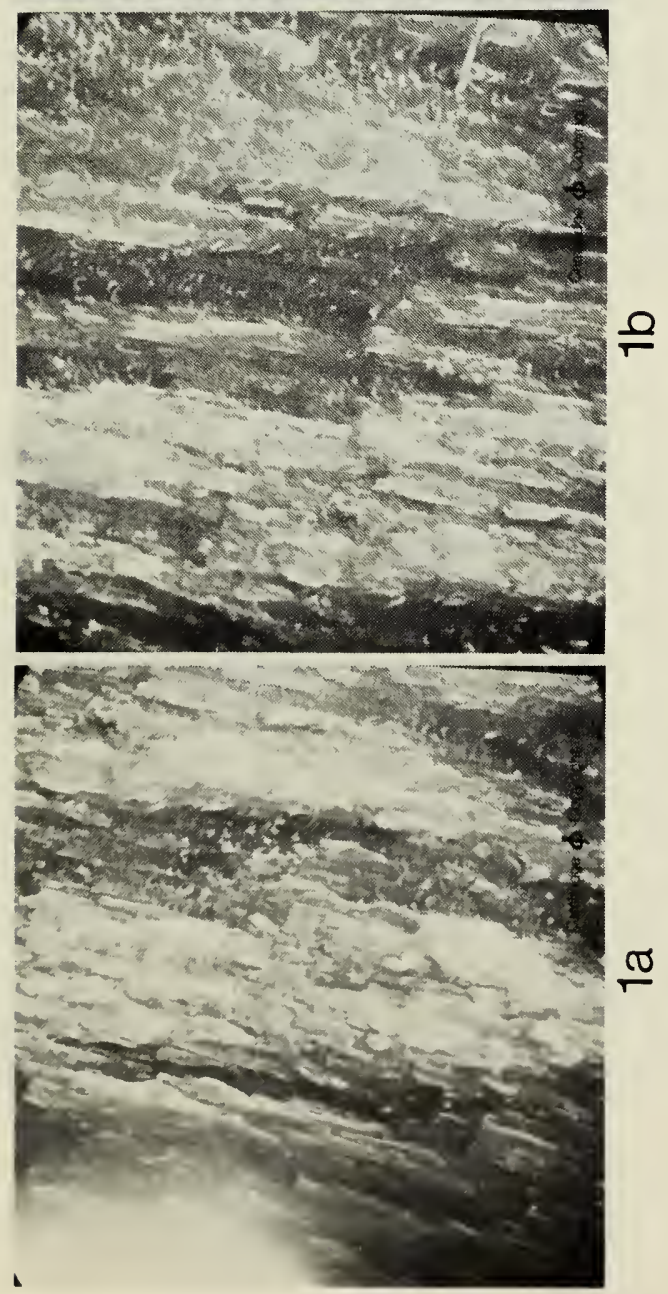
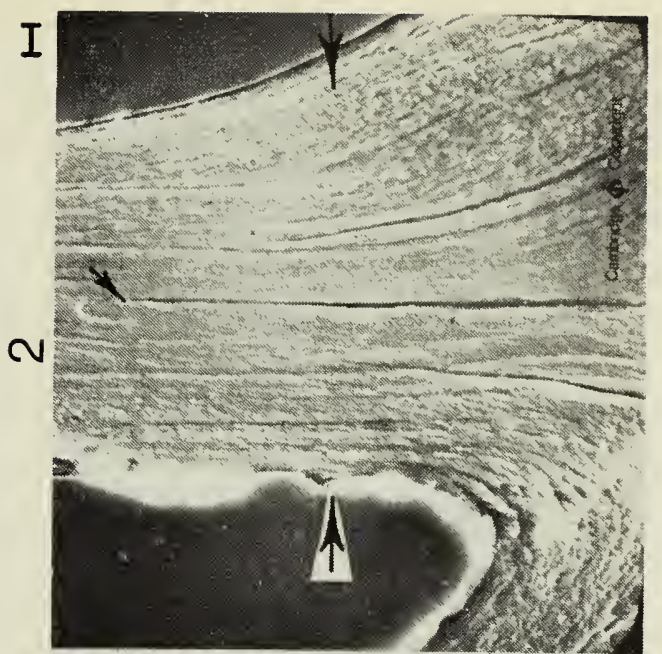

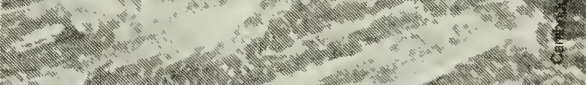

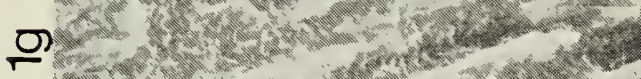

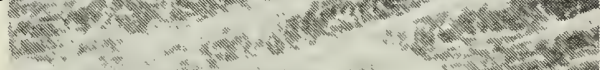
8 (a) and

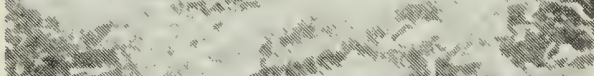

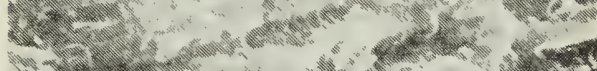

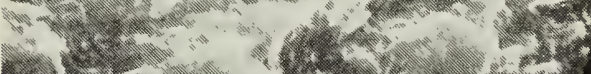

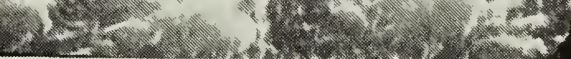

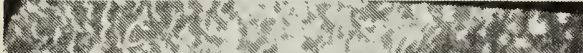

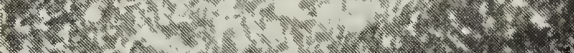

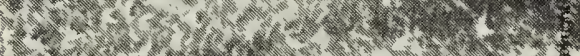

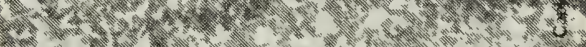

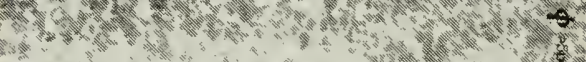

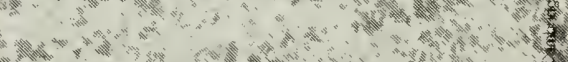

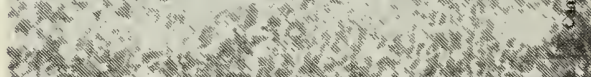

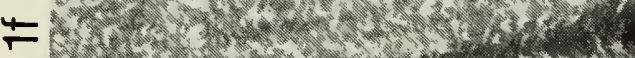

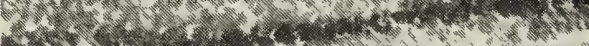

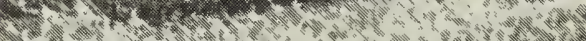

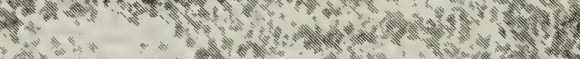

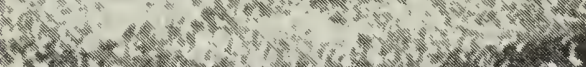

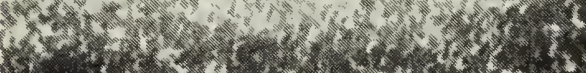

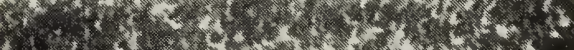

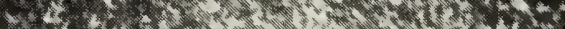

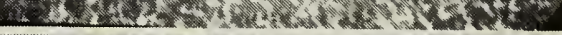

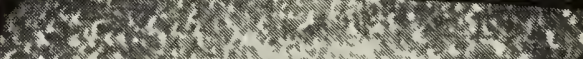

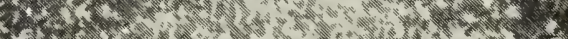

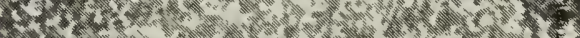

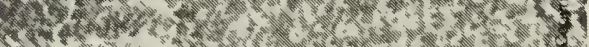

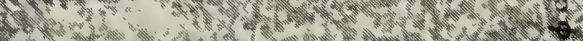

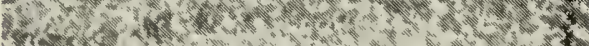

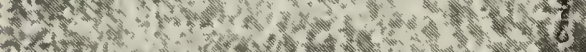

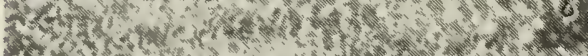

Q

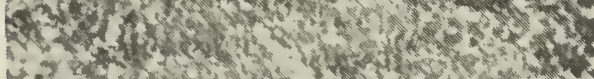

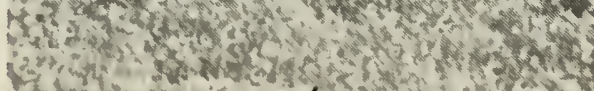

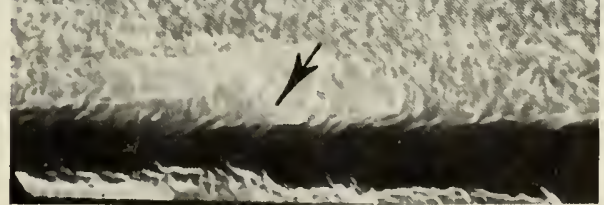


statistically distributed rows of holes support a complete initial mineralization. However, they also add that the holes could have developed in a way analogous to the interglobular space in the apatite of teeth as a result of insufficient mineralization (W. J. Schmidt and A. Keil, 1958, p. 67, $145)$.

\section{Lamellae}

The character of the lamellae is similar within each form-species but varies between form-species. Those in Drepanodus are ill-defined, commonly fused along part of their length, and are variable in thickness. This appears to be a function of the irregular character of the crystallite rods and sheets that build the lamellae. The width of the lamellae ranges from 1-5 $\mu$. The lamellae in Polycaulodus bidentatus are well defined and are of the same size range. The interlamellar spaces are sharp and persistent and with the crystallites parallelling these it is possible to determine small non-persistent microlamellae. Such microlamellae, with rhythmic banding, were also noted by Pietzner et al. (1968, p. 139). They were not observed in either $D$. homocurvatus or Ptiloconus gracilis. In $P$. bidentatus, the lamellae are thinner and more apparent in the outer part of a denticle or cusp than the inner core. This is also in agreement with the observations by Pietzner et al. (1968, p. 139, text-fig. 9, Pl. 23, fig. 4) on the platform conodonts.

Most lamellae are extensive and persistent laterally and most are clearly developed as a complete sheet. In some cases noted earlier, some lamellae are of limited extent and were added at points of more rapid growth. No materials were observed infilling the interlamellar spaces comparable to the local petroleum and pyrite additives reported by Pietzner et al. (1968). The surfaces had of course suffered etching and peel impressions had been taken so there was less likelihood of such phenomena being preserved.

\section{PLATE VII}

Minute sphere structures on longitudinal sections through Polycaulodus bidentatus

Fig. 1 (TEM). Spheres are predominantly aligned in rows along the individual prismatic crystallites; arrow in centre indicates a prominent example. Spheres are of fairly uniform size but vary in their spacing. Scale measures $1 \mu$.

Fig. 2 (SEM). Electron micrograph of spheres using Y-modulation. With this technique, the morphology of the surface is reproduced on the micrograph by a multitude of fine white lines that clarify positive and negative topography. In this figure, the minute circular structures (spheres) are clearly positive, not negative, in relief. Scale measures $1 \mu$.

Fig. 3 (SEM). Close-up view of the spheres illustrating the circular shape, the fairly uniform size, and the tendency to develop in rows along the crystallites. Scale measures $1 \mu$. 




\section{Other structures}

Two other structures are worthy of discussion, both noted in Polycaulodus bidentatus. The centre of the main denticle was represented by a circular empty channel. The circular shape is well shown in the Stereoscan illustrations. In width, the channel varies somewhat but generally diminishes terminally. The tiny pit in the basal excavation, although sealed, is its lowest expression. This growth axis is thus rather capacious and undoubtedly was an important structure in the development of the denticle. It was not observed to be filled with white matter or by the coarsely crystalline apatite that comprises the second notable structure.

The latter is the sheet of coarsely crystalline apatite that is seen to lie on an anterio-posterior plane that bisects the denticles. This material is cut by the growth axis and there is no structural evidence that the sheet is a secondary feature. The significance of this sheet material, whether it is always present in P. bidentatus, and to what extent it is present in other form-species will require further investigation.

\section{"Fibrous" vs. lamellar conodonts}

The selection of the three particular form-species was made largely to attempt to distinguish any distinct structural differences between "fibrous" and lamellar conodonts. Previous workers, notably Lindström (1964, pp. 22-24), have pointed out that the "fibrous" conodonts obviously have a lamellar structure, but morphologically, stratigraphically, and geographically they have certain distinct peculiarities. One main reason for their early separation as a group by Branson and Mehl in 1933 was that most "fibrous" forms fractured along a line parallel to the growth axis instead of normal to it as did the lamellar forms. The "fibrous" appearance was in fact produced by the parallel lamellae. In Polycaulodus bidentatus it

\section{PLATE VIII}

Transverse sections (SEM) through denticles of Polycaulodus bidentatus

Fig. 1 General view illustrating lamellae composed of prismatic crystallites and cusp cut by antero-posterior sheet of coarsely crystalline material. Scale measures $10 \mu$.

Fig. 2 Detail of central part of Fig. 1 with the coarsely crystalline sheet and the small prismatic crystallites. Scale measures $1 \mu$.

Fig. 3 View of coarsely crystalline sheet extending from upper-right corner (see arrow) and cut by the central hollow growth axis (dark area at lower left). Scale measures $1 \mu$.

Fig. 4 Vertical view looking down on central growth axis shown in Fig. 5 illustrating the bifid (twin channel) character (see arrows). Scale measures $1 \mu$.

Fig. 5a-d Composite traverse across the second denticle of a $P$. bidentatus. Horizontal arrow indicates central growth axis. Fig. 5a illustrates lamellae composed of small prismatic crystallites oriented parallel to the interlamellar spaces marked by arrows. Fig. 5c shows the limited lateral extent of microlamellar sheets. No coarsely crystalline sheet present in this denticle. Scale measures $1 \mu$. 

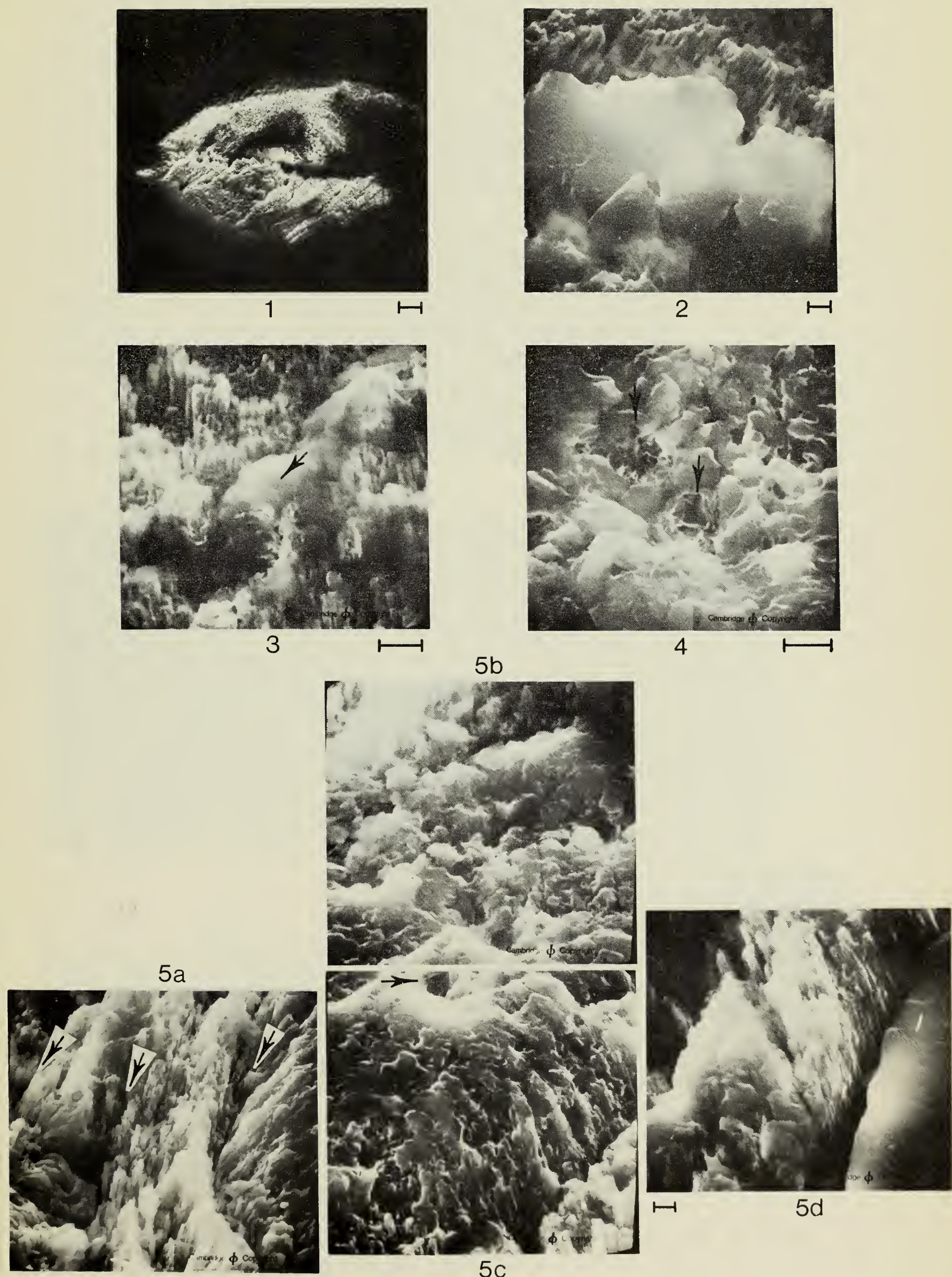

$5 c$ 
was shown that the crystallites are arranged parallel to the interlamellar zones and so lines of weakness are also likely to lie in this direction. Most so-called lamellar forms possess white matter that is layered, in which the crystallites are smaller, and in which some rows of holes lie perpendicular to the growth axis. All these factors assist in producing fracture surfaces that are normal, not parallel, to the growth axis. Again, more studies on other form-species of "fibrous" conodonts will be necessary to determine if all these forms possess certain structural properties distinct from the lamellar conodonts.

In reality, there are probably at least three major groups of conodonts, based on microstructure: the "fibrous" forms, the lamellar conodonts lacking white matter and perhaps better termed "hyaline," and those lamellar conodonts with extensive white matter. Some species, e.g. $D$. homocurvatus, are found both with and without white matter and the presence and abundance of this material may be influenced by environmental factors (e.g. availability of usable phosphate). Much future work will be required in this area also.

\section{Conclusions}

As Lindström (1964, p. 22) noted, the internal structure of conodonts is likely to be of great taxonomic importance. This aspect has been virtually ignored but it is now possible to explore this area with the aid of the electron microscope. This paper represents an attempt to document the internal structure for three important, representative form-species. The results show certain similarities but many significant differences, especially at the crystallite level. The task ahead will be to document many more form-species and also to extend this work stratigraphically and to involve form-species supposedly belonging to the same natural species. Besides being of taxonomic value, such results may hopefully reveal natural phylogenies within conodonts, based on internal structure.

\section{PLATE IX}

Transverse section (SEM) through the base of Ptiloconus gracilis

Fig. 1 General view, black areas at top left, bottom, and centre (basal cavity) are the plastic embedding medium. Lamellae and interlamellar spaces are well developed. Large arrows indicate line of section represented by Figs. 2 a-c. Lamellae are thicker towards margin; some lamellae have only limited lateral extent (see small arrow). Scale measures $10 \mu$.

Fig. 2a-c Composite traverse across line of section indicated in Fig. 1. Two parallel arrows in Fig. $2 b$ define one lamella. Note the irregular flaky crystallites that comprise the lamellae and have rather random orientation. Arrow in Fig. 2c marks a secondary fracture. Scale measures $1 \mu$.

Fig. 3 Detail of crystallites. Note their loose packing, flaky and porous structure, and rather random orientation. Scale measures $1 \mu$. 


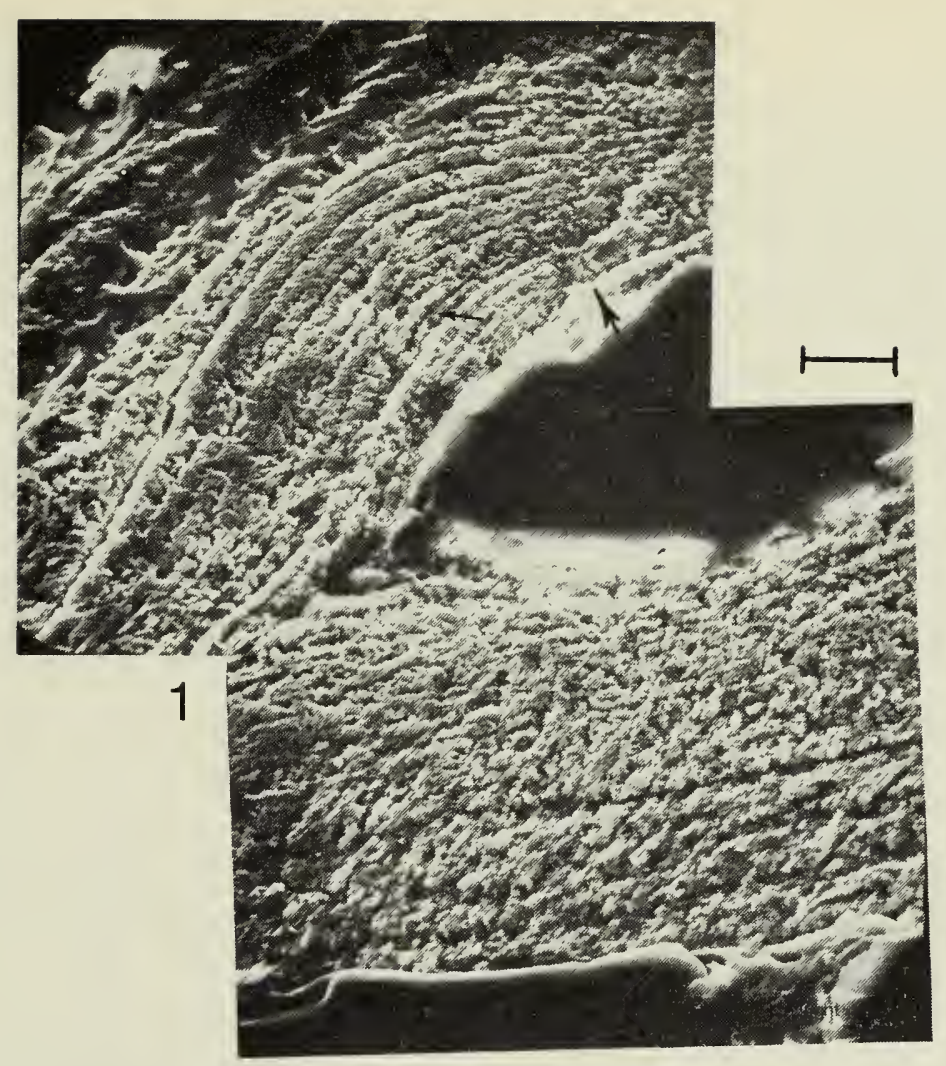

$2 a$

$2 b$

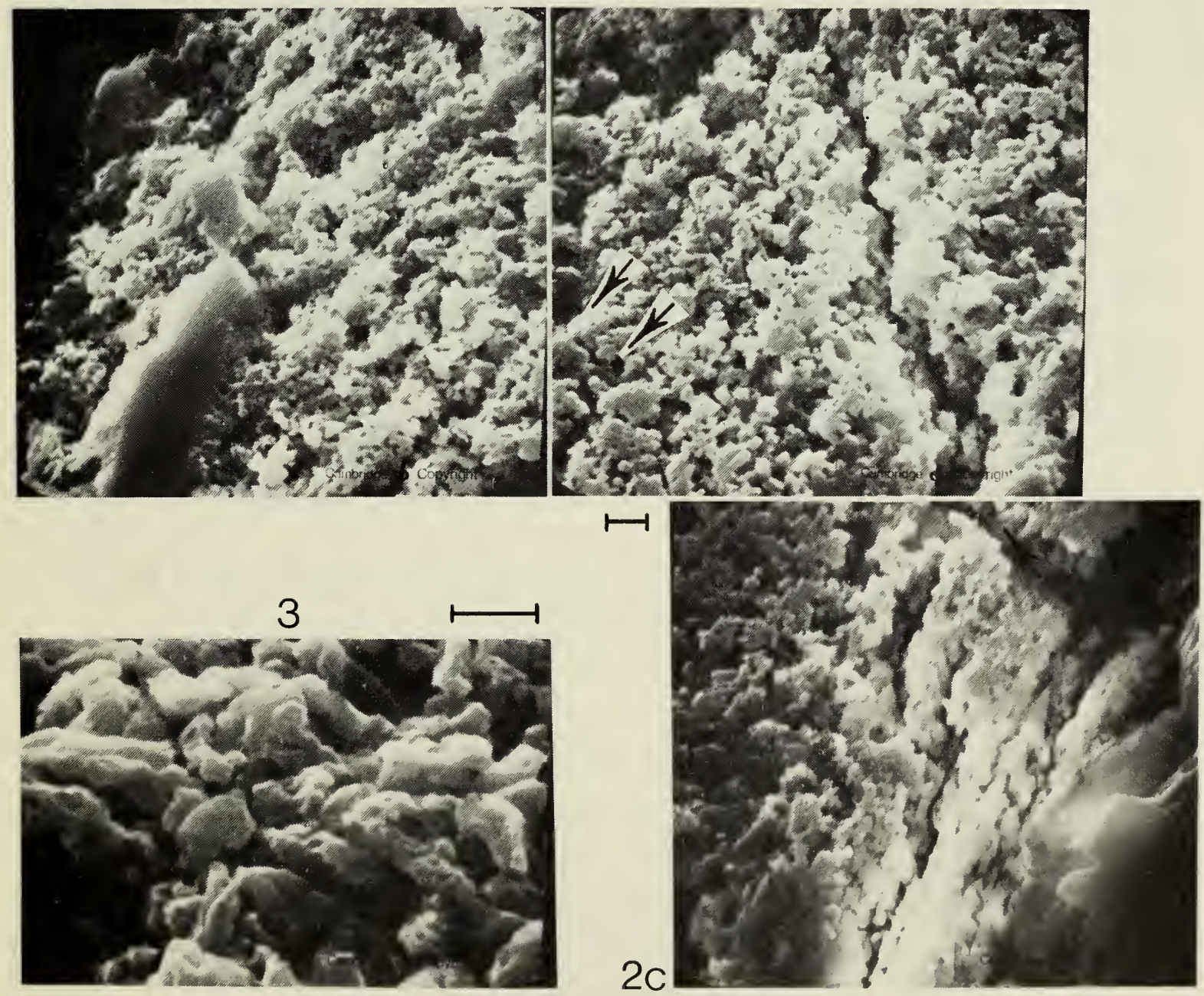




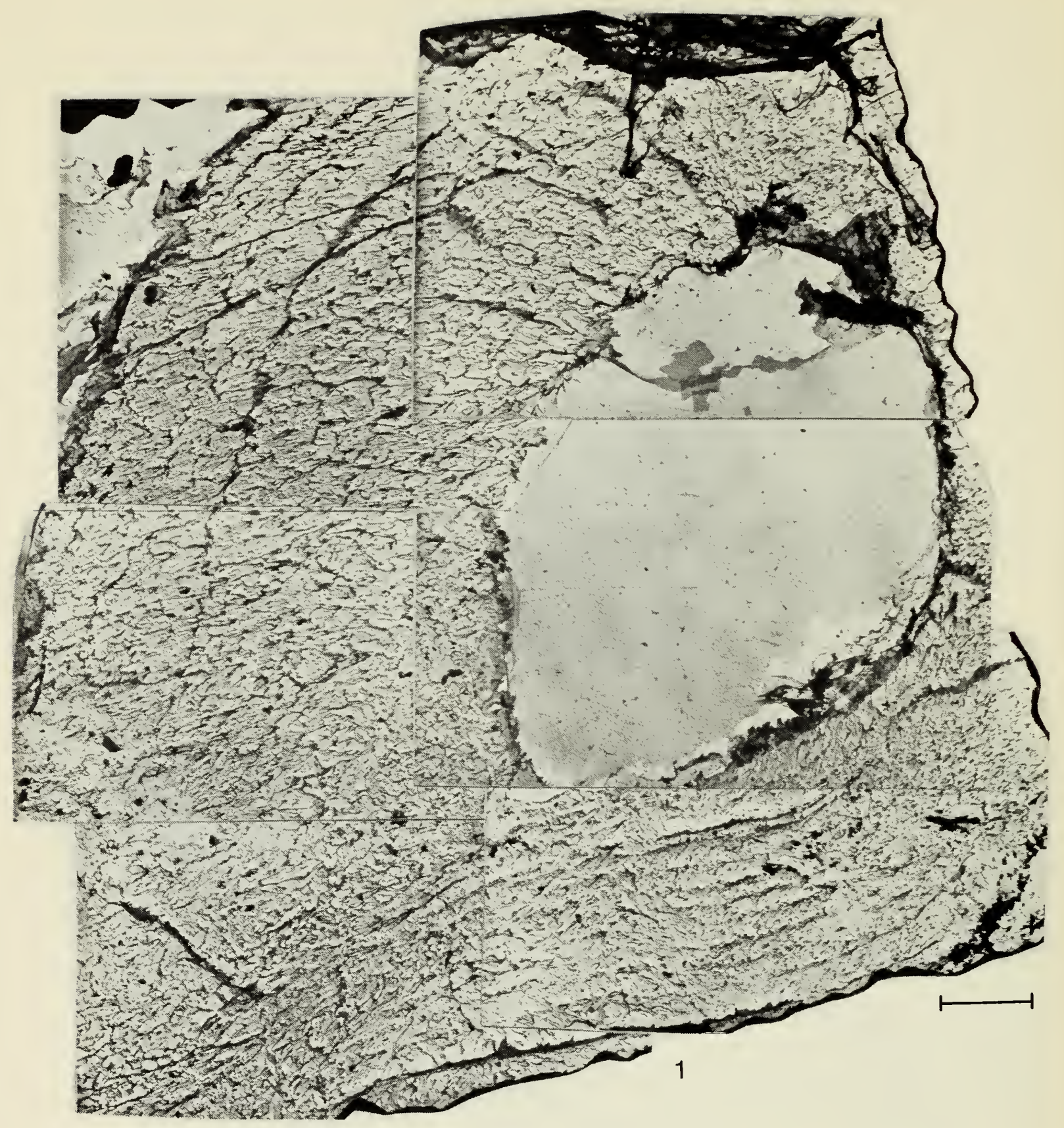

PLATE $X$

Fig. 1 Composite transverse section (TEM) through basal area of Ptiloconus gracilis. Central area is the plastic-filled basal cavity. Individual lamellae are best seen in lower part. The orientation of the crystallites, especially in the upper left area, is predominantly oblique to the interlamellar spaces. Same section, but slightly larger, as that illustrated in Pl. IX, Fig. 1. Scale measures $10 \mu$. 


\section{Acknowledgments}

C. R. Barnes wishes to acknowledge the financial assistance for this continuing study from the National Research Council of Canada. The work of D. B. Sass and E. A. Monroe was supported, in part, by a grant from the Alfred University Research Foundation. Appreciation is expressed to Mr. Clifford Randall for those photographs taken with the Hitachi electron microscope, and to W. C. Sweet, the Ohio State University, and F. H. T. Rhodes, University of Michigan, for critically reading the manuscript.

\section{Literature Cited}

ANDREWS, H. E.

1967 Middle Ordovician conodonts from the Joachim Dolomite of eastern Missouri. Jour. Paleont., vol. 41 no. 4, pp. 881-901.

BARNES, C. R.

1967 Stratigraphy and sedimentary environments of some Wilderness (Ordovician) limestones, Ottawa Valley, Ontario. Canadian Jour. Earth Sci., vol. 4 no. 2, pp. 209-244.

BERGSTRÖM, S. M. AND W. C. SWEET

1966 Conodonts from the Lexington Limestone (Middle Ordovician) of Kentucky and its lateral equivalents in Ohio and Indiana. Bull. Amer. Paleont., vol. 50 no. 229, pp. 271-424.

GROSS, WALTER

1954 Zur Conodonten-Frage. Senckenbergiana leth., vol. 35 no. 1-2, pp. 73-85.

1957 Über die Basis der Conodonten. Paläont. Zeitschr., vol. 31 no. 1-2, pp. 78-91.

1960 Über die Basis bie den Gattungen Palmatolepis und Polygnathus (Conodontida). Paläont. Zeitschr., vol. 34 no. 1, pp. 40-58.

HASS, W. H.

1941 Morphology of conodonts. Jour. Paleont., vol. 15 no. 1. pp. 71-81. KOHUT, J. J.

1969 Determination, statistical analysis, and interpretation of recurrent conodont groups in Middle and Upper Ordovician strata of the Cincinnati region (Ohio, Kentucky, and Indiana). Jour. Paleont., vol. 43 no. 2 , pp. 392-412.

LINDSTRÖM, MAURITS

1955 Conodonts from the lowermost Ordovician strata of south-central Sweden. Geol. Fören. Förh., vol. 76 no. 4, pp. 517-603.

1964 Conodonts. Amsterdam, Elsevier Publishing Co., 196 p.

PANDER, C. H.

1856 Monographie der fossilen Fische des silurischen Systems der russisch-baltischen Gouvernements. Akad. Wiss. St. Petersburg. $91 \mathrm{p}$.

PIERCE, R. W. AND R. L. LANGENHEIM JR.

1969 Ultrastructure of some selected Mississippian conodonts. Geol. Soc. Amer., Abstr. 1969 Pt. 4 (Southeastern Section), p. 63. 
PIETZNER, HORST, JOHANNA VAHL, HANS WERNER, AND WILLI ZIEGLER

1968 Sur chemischen Zusammensetzung und Mikromorphologie der Conodonten. Palaeontographica Abt. A, Bd. 128 pt. 4-6, pp. 115-152.

RHODES, F. H. T.

1952 Recognition, interpretation, and taxonomic position of conodont assemblages. In Moore, R.C., ed. Treatise on invertebrate paleontology, Pt. W., Miscellanea: Lawrence, Kansas, Geol. Soc. Amer. and Kansas Univ. Press, pp. 70-83.

RHODES, F. H. T. AND P. S. WINGARD

1957 Chemical composition, microstructure, and affinities of the Neurodontiformes. Jour. Paleont., vol. 31 no. 2, pp. 448-454.

SCHMIDT, W. J. AND A. KEIL

1958 Die gesunden und die erkrankten Zahngewebe des Menschen und der Wirbeltiere im Polarisationmikroskop. Münschen, Carl Hanser Verlag, 386 p.

SCHOPF, T. J. M.

1966 Conodonts of the Trenton Group (Ordovician) in New York, southern Ontario, and Quebec. Bull. N.Y. State Mus. Sci. Serv., $405,105 \mathrm{p}$.

WEBERS, G. F.

1966 The Middle and Upper Ordovician conodont faunas of Minnesota. Minnesota Geol. Surv. Spec. Publ. SP-4, 123 p. 



(2) 12 
LIBRARY

ROYAL ONTARIO MUSENM 

